\title{
Imereti Region's Natural - Recreational and Historical - Cultural Potential as Tourism Development Factor in Georgia
}

\author{
Davituliani Tsitsino \\ Mikautadze Rusudan \\ Kutaisi Akaki Tsereteli State University, Georgia
}

\begin{abstract}
Imereti - is one of the smallest region on the Black Sea coast in Georgia. The geographical location, historicalcultural and natural monuments, the rich Imeretian hospitality traditions are a good prerequisite for the development of recreation and tourism. Imereti region is a growing tourist segment. For more than 900 historical and more than 350 natural monuments continuously presents the rich history of the country from the primitive societies until nowadays. Myths and legends related to Imereti (Colchis kingdom, myth about Amirani (Prometheus), Golden Fleece, King Aetees and Medea and etc.) are well-known for the Western society. The work done for the popularization of these tourist products has greatly contributed to the growth of both organized and unorganized tourism. $(80,000$ men in 2007 , in 2017 - more than 450,000).Today, tourism in Georgia is developing at a fast pace. Natural and historic monuments are the "Golden Keys" of the tourism potential of the region. We believe that tourism is a stimulus for the development of the local economy, and it should facilitate for staying of youth in the small towns by creating different jobs in order not to leave their country and therefore alienate from their national identities and culture.
\end{abstract}

Keywords: natural monuments; historical-cultural heritage; national identity; recreational resources.

\section{Introduction}

Georgia has an important strategic location in the Caucasus, on the eastern coast of the Black Sea. It contains all elements of recreational resources: the warm sea, mild climate, vast hydrographic network, constant glaciers, karst caves and rich cultural and historical monuments.

Today, Georgia, with its unique culture, traditions, hospitality, natural and historical monuments, attracts more and more attention on the tourist market. Because of its small territory, tourists can fully imagine its natural-recreational resources and historical-cultural heritage.

We'd like to introduce you one of the regions of Georgia, Imereti and to show you its tourist prospects and potential using various visual, scientific and statistical materials. To analyze the issue we have used two scientific views : theory of unbalanced economic growth ${ }^{1}$ (Cooper, et.al, 2008: 248) and Lane's criteria ${ }^{2}$. The first approach is effective especially for developing countries. If investment is implemented in one particular or in several sectors, development of the main field will result in revival, progress and proper functioning of the rest of fields. The second view- Lane's criteria determines the values of the agrotouritic place: 1 . The value and beauty of the landscape 2 . Territories with wild nature. 3. Cultural historical and ethnic heritage, 4. favorable conditions for hunting, fishing and skiing. 5. Customer's access to foreign markets. 6 . Effective and professional advancement and commercial activity management. According to these views such paramount role in Imereti region can be performed by tourism. 


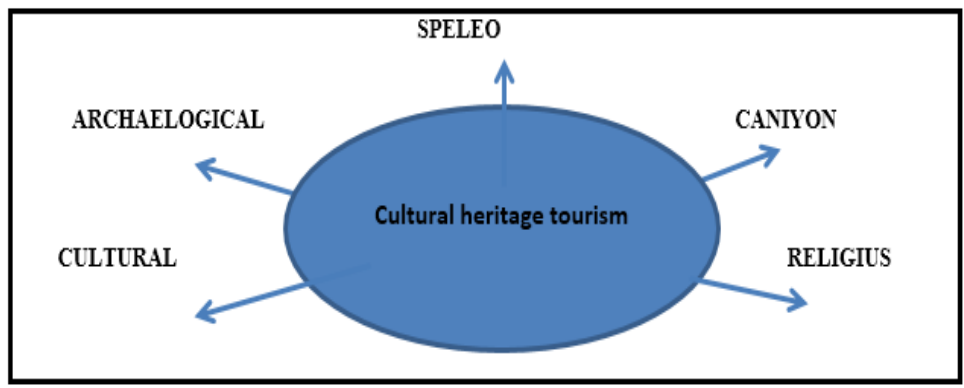

Imereti region is not rich with strategic natural resources, but it can create its own competitive advantage over culture, historical monuments, nature reserves and natural-recreational environment. Therefore, tourism can become one of the main sources of income for the region and promote the development of neighboring fields in the country. For this purpose in 1998-2001years with the participation of foreign and Georgian experts was elaborated National Tourism Development Strategy and in 2012 was designed tourism development and marketing plan for the Imereti region and was proposed a series of actions to be implemented to improve the contribution of tourism for the local population's economic and social life

The diagram shows cultural tourism destinations which can be found in Imereti.

\section{Imereti natural sights and their perspectives}

Imereti Nature is a major factor for the tourism development. At present, 4 categories of the protected areas are located in the study area. According to the data of the last 10 years, most visitors $-1108503 \mathrm{mln}$, in the protected areas are registered in 2018, while this figure was 12226 in 2008, that means that the number of tourists in the last 10 years increased 91 times $^{3}$.

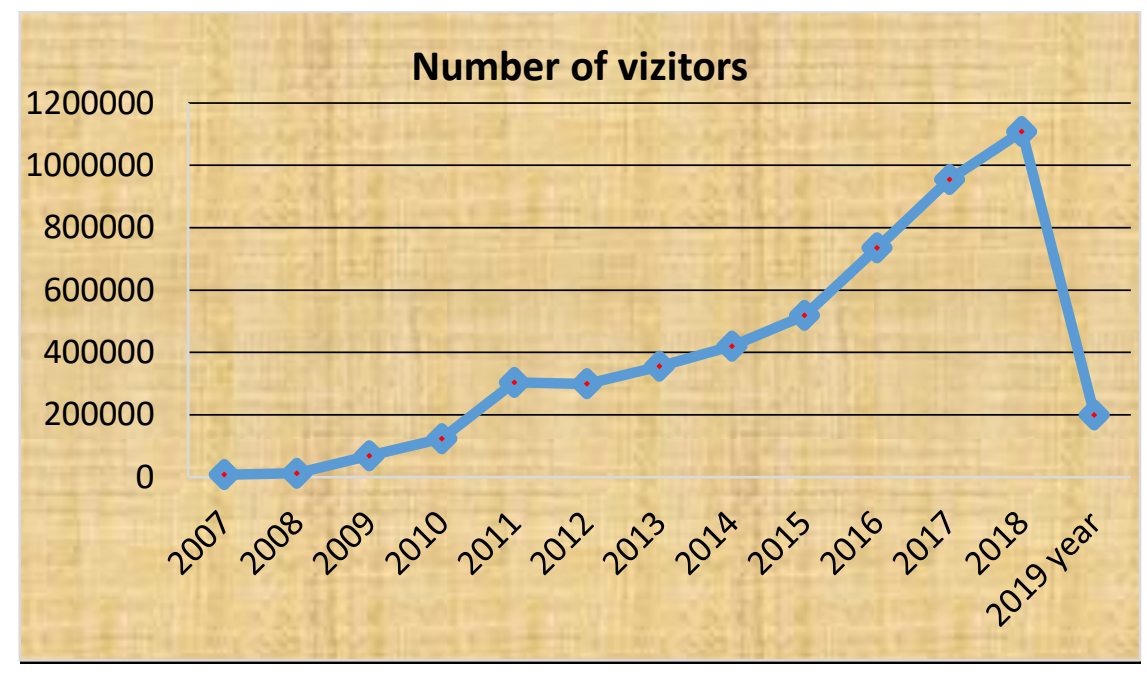

Imereti region is particularly rich with karst caves. There are up to 1000 karst funnels only in Kutaisi surroundings. Taking into consideration this fact, Georgia adopted the Law on the Creation and Management of Imereti Caves Protected Areas (June 21, 2011, \# 4864). It includes Sataplia Nature Reserve, Sataplia Managed Reserve, Natural Monument of Prometheus Cave, Ocatse Canyon Nature Sight and other 17 different sights of nature. Now information about Imereti Cave Protected Areas of Georgia is available on the official web-site of International Show Caves Association (ISCA) ${ }^{4}$. 
The most attractive objects for tourists are Prometheus and Sataplia caves with well-equipped infrastructure. Visitors are amazed with breathtaking views of stalactites of unique forms, stalagmites, petrified waterfalls, underground rivers and lakes. You can have a trip by boat on the underground river.

Sataplia complex protected area has preserved a prehistoric nature with wooden relics, labyrinths of karst caves and fossilized tracks of dinosaurs. There are only 3 places in the world where you can find such traces of dinosaurs, and one of them is in Sataplia. The central point for the tourists is the "Stone heart"- a huge heart shape stalagmite. Tourists make a wish near the "sculpture".

An observation deck at the highest point of the Sataplia reserve with a transparent floor, opens up a breathtaking view of the surroundings of Kutaisi and Colchis valley.

Very special is Tsutskhvati cave located $24 \mathrm{~km}$ from Kutaisi, which has no analogy in the world. The cave consists of 13 floors. Unfortunately, due to its complexity, the cave is not very popular among tourists, but it is a great place for extreme tourism lovers.

Imereti caves microclimate and stable temperature are accessible and useful for 76 different diseases, including bronchial asthma, hypertonic and hypotonic diseases. Nowadays, Czech specialists have chosen Satsurblia Cave for speleorecreational purposes which will receive the first visitors from this spring. We assume that people with respiratory tract problems will be able to perform different treatments in this healing place.

Nowadays, untrapped caves for extreme speleotourism are few in the world, so the caves of Imereti region can be very interesting for them. In order to develop extreme tourism, the region is rich in mountain rivers too, where rafting can be developed.

The Okace canyon is one of the most popular attraction among tourists. Recently built high quality tourist infrastructure offers tourists magnificent views to the canyon and its surroundings especially in spring, when everything is green and in blossom. Nearby, one can find the tallest waterfall of Georgia - Kinchkha together with another water abundant waterfall nearby.

This diagram shows the number of visitors by protecting areas in 2018. Imereian natural monuments are in the top ten. ${ }^{5}$

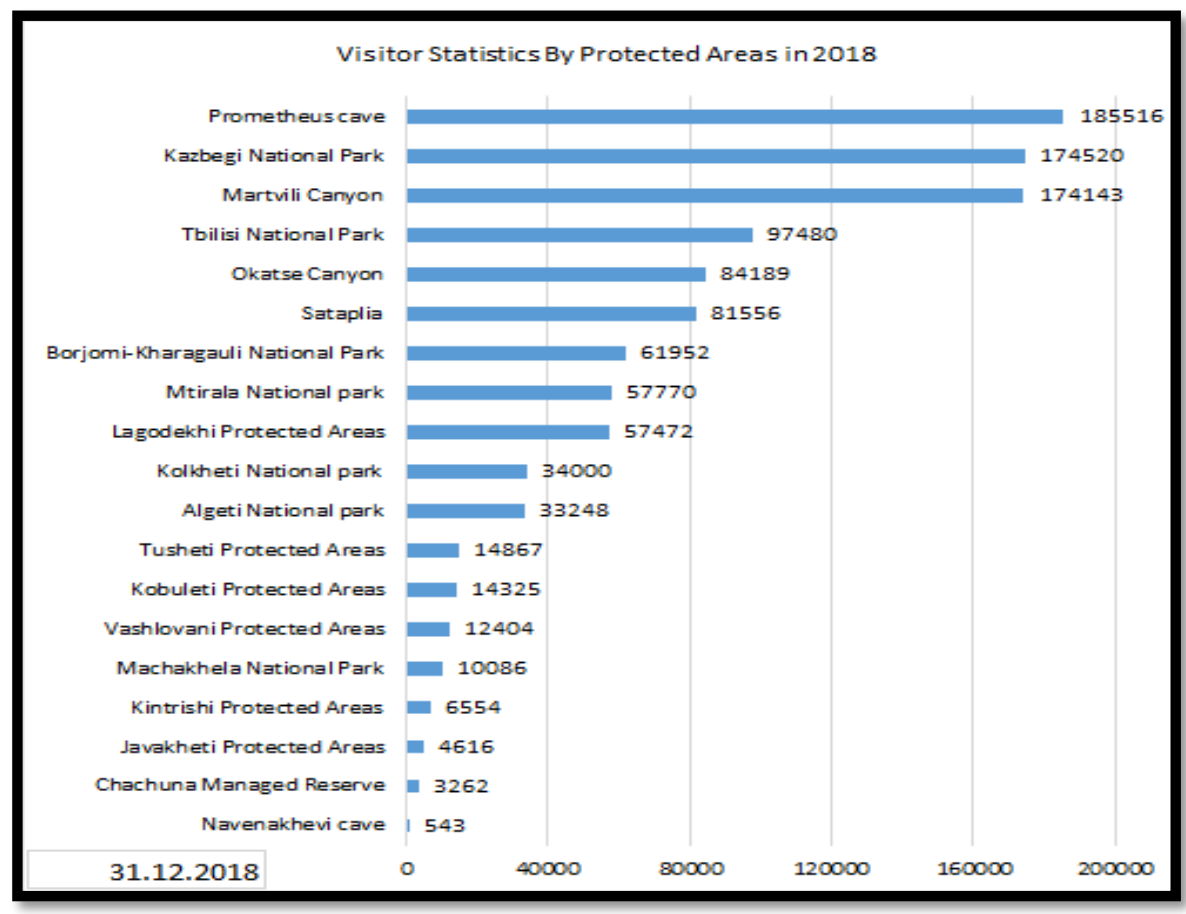


The growth of tourism in these places successfully affected on the local population of the high mountain villages of Gordi and Kinchkha. Earlier village Gordi was the health resort for children and native people were involved in different activities including renting their houses. This experience helps them to manage their small businesses. Local small businesses collaborate with touristic agencies and tour operators which ensure constant visits of tourist groups. They are aware of the strategy of success of their own activities and try to satisfy the regular visitors in order to increase their number in future. However, it would be noted that if the state and regional authorities are interested in gradual growth of agrotourism in this part of Imereti, it will allow local residents to use more their resources intensively to enlarge the number of small farms and make them attractive to tourists in order to increase their income. ${ }^{6}$ (Kharaishvili,2017: 368).

Little awareness of tourism potential in the region directly effects on the structure of tourism sector in Imereti. The local population is often unable to understand the significance of Imereti's natural monuments as a tourist destination for the future. The problem is pollution of the sights with household waste by community members, in times carst funnels are used as landfills by locals. Local authorities must conduct meetings and trainings to increase their awareness on these issues, involve them in local tourism infrastructure management and take strict measures against environmental pollution.

\section{Historical-Cultural and Religious Tourism Development Perspectives}

$70 \%$ of tourists around the world travel to see the cultural heritage sites. Heritage is cultural diversity and the best way to see the links between cultures. When cultural heritage tourism in the region develops properly, it helps the region to protect and save country's natural and cultural treasures and improve the quality of life of local residents. It has economic impact on the local level by creating new jobs and small businesses, increases the pride and interest of the local population in tourism. The increase of tourism flow gives opportunity to promote the protection and maintenance of cultural heritage monuments ${ }^{7}$. (http://icomos.org.ge/ge/wp-content/uploads/publicationPolicy_GE.pdf)

The cultural-historical potential of Imereti includes: archaeological sites and historical towns, numerous ecclesiasticl and civic architecture, museums and other sites. Visiting the unique historical monuments is a great motivation for tourists to get acquainted with the history and culture of Georgia which due to its geopolitical location, represents the place of meeting of Eastern and Western cultures.

Kutaisi and its surroundings in Imereti tourism industry are important attraction. The city is located along the banks of the river Rioni. Its age varies from 3000 to 3500 years. The city and its surroundings are rich in natural, archaeological and historical-cultural heritage monuments. ${ }^{8}$. (http://kutaisi.gov.ge/ge/turizmi) Due to its diversity, cognitive tourism in this city can really become an essential part of economic development.

The main attraction in the city is Bagrati Cathedral, built in 1003, as a symbol of unity of Georgia. Here are represented archaeological layers from the first millennium to the present day. Bagrati Cathedral, along with the Gelati monastery complex, was included in UNESCO World Cultural Heritage List in 1994. Unfortunately, after its hastily reconstruction by the government, the cathedral lost its authenticity and in 2017 UNESCO removed it from the World Cultural Heritage List which was a huge loss. Nevertheless, the monument still makes a great impression on the visitors.

Nowadays, Cultural Heritage Protection Agency of Georgia and the Polish archaeological expedition lead an intensive work to enter Kutaisi as a "cultural landscape" into the UNESCO World Heritage List. Kutaisi, as one of the oldest cities in the world, satisfies all these criteria. In this case there is a chance that the Bagrati Cathedral will return to the UNESCO nomination. As a result of recent archaeological studies, the materials found on "Gabashvili and Dateshidze Gorges" dates back to XII-VIII centuries BC, which proves that Colchis's civilization was really existed around Kutaisi. This fact is another motivation that archaeologists' work will be finished successfully.

Six $\mathrm{km}$ from Kutaisi is located the Motsameta Monastery Complex, which dates back to the eighth century (and 11 kilometer from Kutaisi is situated the Gelati Monastery Complex, built in the first half of the 12th century by the greatest Georgian King David Aghmashenebeli or David the Builder as "New Athene and Other Jerusalem". It is listed on World Cultural Heritage from 1994. The main cathedral is distinguished with a monumental mosaic that is a high-artistic design art. ${ }^{9}$ http://www.dzeglebi.ge )

In the Kutaisi suburb is the ruins of Geguti royal palace. The importance of the ruins of the Geguti palace is emphasized by its largely secular nature as most of the surviving monuments of medieval Georgian architecture are churches and 
monasteries. In 2015, there was installed a special glass construction, which allows the viewer to see the monument in its original form. This technology is unique in our country..$^{10}$ (http: // sputnik-georgia.com).

There is still a lot to do in the direction of cultural heritage tourism. There is no appropriate coordination among the state, church and local population to make these tourist destinations more attractive in identifying the country through cultural monuments. It is urgent to improve the existing infrastructure, ecumenical relations between the tourists, church and local representatives, to protect the reliability of the information about cultural heritage monuments, which is provided to tourists because, unfortunately, some foreign guides, who accompany tourism groups, distort the history and culture of our country.

In Imereti, tourists are interested in Antique City Suriumi, today's Vani (VII-I centuries BC) which is located on the 40-minute drive from Kutaisi. Although only a third of the site has been studied, it has produced an astonishing number of artifacts: temples and sacrificial altars, Colchis pottery, imported Greek luxury items, graceful bronze sculptures and exquisite golden jewellery. Despite their diversity, the gold ornaments found at Vani are characterized by unity of style and technique, which clearly points to their belonging to a Colchian school of art. ${ }^{11}$ (http://vani.org.ge/municipality)

While researching the tourism potential of Imereti, it is important to determine the role of sustainable tourism for overcoming the poverty of the local population. It is worth noting, that this direction is particularly related to the issues of developing countries where income is scarce and unstable. According to Geostat data, in 2016 the share of population, which was below the absolute poverty line, was $21,3 \%$. The poverty rate is especially high in rural areas. We have studied several dissertations and scientific works on this issue ${ }^{12}$ (T. Doghonadze, (2018: 69); Kharaishvili E (2017) Devidze Eka. http://www.nplg.gov.ge/dlibrary/collect/0002/000609/Devidze\%20E.pdf;) to find out which part of local population has gained the benefits from tourism. It appeared that touristic development in the region is mostly effectively reflected on non-poor families, which have a small amount of initial capital. They have the initiative to combine their material and socialintellectual resources and through labor diversification get benefits from tourism. Poor population is less successful in this regard.

Studies show that after the amenities of tourist monuments in the region were created new family hotels, increased the number of renting vehicles, opened catering facilities, appeared additional jobs.

Nowadays one of the distinguished role in touristic business belong to the cuisine. Georgian cuisine - Imeretian Khachapuri, Khinkali, Kupati, Satsivi, Wine and Churchkhela are popular among foreign visitors. In the hot tourist season, there are loads of food facilities nearby tourist attractions which promotes the growth of local population income. Studies show that Kutaisi is the leader in variety of Georgian cuisine and gourmet food. ${ }^{13}$ /Kharaishvili E. (2017: 373/

According to the influential edition Bloomberg report in 2017, Georgia ranks second among the fastest growing tourist destinations in Europe with an increase of $+27.9 \%$. They claim that Georgian traditional dishes are the best reason to visit Europe Untouched corner."14 (https://www.geotourism.ge/news/evropasi-yvelaze-swrafad-mzard-turistul-qveynebi 2018).The growth of tourism potential of Kutaisi and its surroundings has significantly contributed to rehabilitation of Davit Aghmashenebeli International Airport in 2012, from which flights are available in any weather and visibility. The airport is the first international airport in the region, offering cost-efficient airline services, which greatly influenced on increase of tourists flow from Europe and Asia ${ }^{15}$ (https://www.geotourism.ge/news/wizz-air).

Nowadays in the development of Imereti tourism prevails the inner tourism. This is probably due to its geographical location. Imereti mostly serves as a link between other regions of the country. However, the State representativeGovernor's Administration in Imereti and Kutaisi City Hall do much to make Imereti and Kutaisi more attractive for foreign tourists and increase their awareness on the international tourism market.

\section{Recommendations and conclusion}

However, there are a number of factors that have a negative impact on tourism development, namely: Imereti tourism system lacks competitiveness in certain aspects. This concerns the infrastructure that needs perfection. There is lack of activities which can be interesting for tourists. Besides, it is essential to improve employees' skills and experience who work in the sector, to promote and stimulate the work of tourist agencies and tour operators, good advertising has paramount importance in order to increase awareness about the region and create desirable image on tourist market. The sector needs more support and regulation from the government. There is weak coordination between administration, private business and native population. Unavailability in marketing information prevent them to conduct their commercial 
work in an effective way. It would be fruitful if we engage local residents in different tourism activities, provide goal-seeking trainings and consultations. Proper management will enable us to increase the number of visitors and social-economic benefits for the local population.

Taking into account existed touristic potential of Imereti region we can arrive to the conclusion that tourism can become an essential part of the economic development for such a small region as Imereti, which will support the preservation of natural-recreational and historical-cultural heritage, increase employment of local population, social activity and income of communities, contribute to the development of small businesses, create healthy competition in marketing and facilitate to develop new international programs and projects.

\section{References}

[1] Cooper Ch.,Flether J., Fyall S.,Gilbert D.,and Wanhill S.\{2008). Tourism: Principals and Practicies. Prentice Hall.

[2] Lane B. (1994).Whatnis Rral Tourism. Journal of Sustainable Tourism Vol.2 \# 7

[3] www.APA.GE

[4] http://www.i-s-c-a.com/show-cave/131-imereti-caves

[5] www.APA.GE

[6] Kharaishvili E. Agrotouristic Areas Assessment with the Lane Criteria and the possibilities for Economic Development of Related Sectors Geography in Glbal Context: Achievements and Challenges. Collected Papers. 2017. Kutaisi. Akaki Tsereteli State University

[7] ICOMOS, International Cultural Tourism Charter. Principles and Guidelines For Managing Tourism At Places Of Cultural And Heritage Significance. ICOMOS International Cultural Tourism Committee. 2002. http://icomos.org.ge/ge/wp-content/uploads/publicationPolicy_GE.pdf

[8] http://kutaisi.gov.ge/ge/turizmi

[9] http://www.dzeglebi.ge/

[10] http: // sputnik-georgia.com

[11] http://vani.org.ge/municipality/

[12] Tatia Doghonadze, The Spstial Aspects and Pecularisies of Sustainable Tourism Development in the Imereti Region, an abstract from the presented dissertation for obtaining the academic degree of Doctor of Geography,Kutaisi, 2018 p. 69; Devidze Eka. Cultural heritage and Tourism Development problems in Inereti Region. Dissertation for obtaining the academic degree of Doctor of Business Administration. http://www.nplg.gov.ge/dlibrary/collect/0002/000609/Devidze\%20E.pdf; Kharaishvili E. Agrotouristic Areas Assessment with the Lane Criteria and the possibilities for Economic Development of Related Sectors Geography in Glbal Context: Achievements and Challenges. Collected Papers. 2017. Kutaisi. Akaki Tsereteli State University

[13] Kharaishvili E. Agrotouristic Areas Assessment with the Lane Criteria and the possibilities for Economic Development of Related Sectors Geography in Glbal Context: Achievements and Challenges. Collected Papers. 2017.Kutaisi. Akaki Tsereteli State University

[14] https://www.geotourism.ge/news/evropasi-yvelaze-swrafad-mzard-turistul-qveynebi 2018

[15] 15.https://www.geotourism.ge/news/wizz-air 